\title{
Trade Effects Based on General Equilibrium
}

\author{
Baoping Guo ${ }^{1}$
}

\begin{abstract}
The Rybczynski theorem describes the trade effect within production analyses between factor endowments and outputs. The Stolper-Samuelson theorem focuses on cost analyses between factor reward and commodity price. This paper examines the trade effect of changes of factor endowments on prices, based on general equilibrium. The study shows that changes of factor endowments cause domestic output changes (the Rybczynski effect), which affect output prices and factor prices (the Stolper-Samuelson effect). It is like a chain of effects that the Rybczynski's trade effect triggers the Stolper-Samuelson's trade effect. The analysis of this paper shows that a small increase of a factor endowment of any country rewards another factor and the commodity using the latter factor intensively. It displays a tuneful circle. Trade brings a well-balanced development to the world.
\end{abstract}

Keywords: E; Factor price equalization; Heckscher-Ohlin; Equilibrium price; equalized factor price.

JEL Classification: F10, F20.

\section{Introduction}

The trade effects are very important parts of Heckscher-Ohlin theories. The Rybczynski theorem addressed the trade effect of factor endowments on output. The Stolper-Samuelson theorem states the trade effects of commodity price on factor price. There are fewer of literature talk about trade effects of changes of factor endowments on prices. This is due to no consolidated expression of price-trade equilibrium.

Dixit-Norman (1980)'s Integrated World Equilibrium (IWE) is remarkable to characterize equalized factor price. They illustrated that if the allocation of factor endowment of two countries changed within IWE box, the factor price and commodity price should remain the same. Guo (2005) initial his study on the possible structure of equalized factor price. Recently, Guo (2018) proposed a general equilibrium of trade on the Heckscher-Ohlin $2 \times 2 \times 2$ model. The equalized factor price at the equilibrium is just also the factor price Dixit-Norman predicted.

This study investigates the trade effect of changes of factor endowment on prices, by using the trade equilibrium Guo (2018) proposed. It is a cross trade effect from production on cost.

This paper is divided into four sections. Section 2 reviews the general equilibrium of trade (Guo 2018). Section 3 presents the trade effects of changes of factor endowments on factor price, commodity price, and commodity output. Section 4 is a discussion.

\section{Review of general equilibrium of the Heckscher-Ohlin Model by IWE approach}

Guo (2018) proposed an approach to study the trade equilibrium by identifying a trade box on Dixit-Norman (1980) integrated world equilibrium (IWE) diagram. We review his work briefly in the following. With the normal assumptions, a standard 2x2x2 Heckscher-Ohlin model is presented as followings:

$a$. The production constraint of full employment of resources is

\footnotetext{
${ }^{1}$ Former faculty member of College of West Virginia, corresponding address: 8916 Garden Stone Lane, Fairfax, VA 22031, USA. Email address: bxguo@yahoo.com.
} 
$A X^{h}=V^{h} \quad(h=H, F)$

where $\mathrm{A}$ is the $2 \times 2$ technology matrix, $X^{h}$ is the $2 \times 1$ vector of commodities of country $\mathrm{h}, V^{h}$ is the $2 \times 1$ vector of factor endowments of country $\mathrm{h}$. The elements of matrix $\mathrm{A}$ is $a_{k i}, k=K, F, i=1,2$.

$b$. The zero-profit unit cost condition is

$A^{\prime} W^{*}=P^{*}$

where $W^{*}$ is the $2 \times 1$ vector of factor prices, $P^{*}$ is the $2 \times 1$ vector of commodity prices. Both $P^{*}$ and $W^{*}$ are world price when factor price equalization happened.

c. The definition of the country h's share of GNP to world GNP is,

$s^{h}=P^{\prime} X^{h} / P^{\prime} X^{W}$

d. The trade balance condition is

$P^{\prime} T^{h}=0$

or

$W^{\prime} F^{h}=0$

where $T^{h}$ is the $2 \times 1$ vector of export of commodity, $F^{h}$ is the $2 \times 1$ vector of factor content of trade.

$e$. The constraint of the cone of diversification of factor endowments(1)

$\frac{a_{K 1}}{a_{L 1}}>\frac{K^{H}}{L^{H}}>\frac{K^{F}}{L^{F}}>\frac{a_{K 2}}{a_{L 2}}$

f. The constraint of commodity price limits(2)

$\frac{a_{K 1}}{a_{K 2}}>\frac{p_{1}^{*}}{p_{2}^{*}}>\frac{a_{L 1}}{a_{L 2}}$

g. The home country's GNP share limits

$s_{b}^{H}=\frac{K^{H}}{K^{F}+K^{H}}, \quad S_{a}^{H}=\frac{L^{H}}{L^{F}+L^{H}}$

where $s_{b}^{H}$ is the upper limit of the home country GNP, $s_{a}^{H}$ is the lower limit of GNP.

By adding the shares of GNP limits on the IWE diagram, using a simple utility function to maximize two countries' distributable GNP on trade box, it obtained the competitive share of GNP of the home country as

$S=\frac{1}{2} \frac{K^{H} L^{w}+K^{w} L^{H}}{K^{w} L^{w}}$

It is just the middle point of the GNP boundaries. He interpreted the result that the best welfares of two countries avoid the hurts of extreme trade at $s_{b}^{H}$ or $s_{a}^{H}$ as far as possible. When taking a share of GNP as $s_{b}^{H}$, then $w^{*}=0$; and when taking a share of GNP as $s_{a}^{H}$, then $r^{*}=0$. The middle point is a good position to reward both factors fairly based on existing factor endowment supplies.

With the share of GNP of the home country by equation (2-9), it obtained the general equilibrium of trade of the Heckscher-Ohlin model as

$r^{*}=\frac{L^{w}}{K^{w}}$

$w^{*}=1$ 
$p_{1}^{*}=a_{k 1} \frac{L^{w}}{K^{w}}+a_{L 1}$

$p_{2}^{*}=a_{k 2} \frac{L^{w}}{K^{w}}+a_{L 2}$

$F_{K}^{H}=\frac{1}{2} \frac{K^{H} L^{w}-K^{w} L^{H}}{L^{w}}$

$F_{L}^{H}=\frac{1}{2} \frac{K^{H} L^{w}-K^{w} L^{H}}{K^{w}}$

$X^{H}=A^{-1} V^{H}$

$X^{F}=A^{-1} V^{F}$

All the endogenous variables $\left(p_{1}^{*}, p_{2}^{*}, w^{*}, r^{*}, x_{1}^{H}, x_{2}^{H}, x_{1}^{F}, x_{2}^{F}\right.$, and $\left.s\right)$ in the model are expressed by exogenous variables $\left(K^{h}, L^{h}, K^{w}, L^{w}\right)$. The equalized price at the equilibrium is just the Dixit-Norman's IWE factor price that if the allocation of the factor endowments for two countries in the IWE box changes, the factor price and the commodity price will remain the same.

The solution for a giving IWE box is unique since there is only one trade equilibrium point in IWE diagram that made the angle of trade equal to the angle of world factor endowments in the IWE diagram. In addition, the equilibrium solution implies that world resources (factor endowments) determine world prices.

\section{Trade effects of changes of factor endowments}

The Rybczynski theorem describes the relationship between commodity output and factor input, holding output price. With the general equilibrium of trade in the last section, we know that equalized factor price and common commodity prices are functions of factor endowments. We can process a trade effect without holding any variables unchanged. The trade effects we talk here is an interactive relationship between endogenous variables (commodity outputs and prices) and exogenous variables (factor endowments).

\subsection{Trade effects of changes of factor endowments on factor price}

Differentiating the relative factor price in equations (2-10) with respect to world capital yields,

$\frac{\partial r^{*}}{\partial K^{w}}=-\frac{L^{w}}{\left(K^{w}\right)^{2}}$

It shows that

$\frac{\partial r^{*}}{\partial K^{w}}<0$

Differentiating equations (2-10) with respect to world capital yields,

$\frac{\partial r^{*}}{\partial L^{w}}=\frac{1}{K^{w}}$

It shows that

$\frac{\partial r^{*}}{\partial L^{w}}>0$

Similarly, we can obtain the trade effect respect to factor endowments of each country $K^{h}, L^{h}, K^{F}, L^{F}$ as

$$
\begin{array}{ll}
\frac{\partial r^{*}}{\partial K^{h}}<0 & (h=H, F) \\
\frac{\partial r^{*}}{\partial L^{h}}>0 & (h=H, F)
\end{array}
$$


$r^{*}$ is relative price respect to $w^{*}$ here.

\subsection{Trade effect of changes of factor endowments on commodity price}

We express a relative commodity price as the following, by using equation (2-12) and (2-13)

$\frac{p_{1}^{*}}{p_{2}^{*}}=\frac{a_{1 k} L^{W}+a_{1 L} K^{W}}{a_{2 k} L^{W}+a_{2 L} K^{W}}$

Analyses of relative commodity price will be more convenient for later presentations.

The changing of factor endowments may have effects both on the commodity price and on factor price. Therefore, this may have some effects on the technological coefficient $a_{i k}$. However, by the envelope theorem, any small movement of the unit requirement of a factor will not violate the isoquant. We will ignore possible substitutions and elasticities in production caused by the small changes in this study.

Differentiating the relative commodity price in equations (3-7) with respect to world capital yields,

$\frac{\partial \frac{p_{1}^{*}}{p_{2}^{*}}}{\partial K^{w}}=\frac{\left(a_{1 L} a_{2 K}-a_{2 L} a_{1 K}\right) L^{W}}{\left(a_{2 L^{L}} L^{W}+a_{2 L} K^{W}\right)^{2}}$

By the specification of this paper, commodity 1 is the relatively capital intensive as

$\frac{a_{1 k}}{a_{1 L}}>\frac{a_{2 K}}{a_{2 L}}$

so,

$\left(a_{1 L} a_{2 K}-a_{2 L} a_{1 K}\right)<0$

This means

$\frac{\partial \frac{p_{1}^{*}}{\partial K_{2}^{*}}}{\partial K^{w}}<0$

Similarly, differentiating equations (3-7) with respect to world labor yields,

$\frac{\partial \frac{p_{1}^{*}}{p_{2}^{*}}}{\partial L^{W}}=-\frac{\left(a_{1 L} a_{2 K}-a_{2 L} a_{1 K}\right) K^{W}}{\left(a_{2 k} L^{W}+a_{2 L} K^{W}\right)^{2}}$

We obtain

$\frac{\partial \frac{p_{1}^{*}}{p_{2}^{*}}}{\partial L^{w}}>0$

We can also obtain the trade effect respect to factor endowments of each country $K^{h}, L^{h}$ as

$\frac{\partial \frac{p_{1}^{*}}{p_{2}^{*}}}{\partial K^{h}}<0$

$$
(h=H, F)
$$

$\frac{\partial \frac{p_{1}^{*}}{p_{2}^{*}}}{\partial L^{h}}>0$

$(h=H, F)$

\subsection{Trade effect of Changes of factor endowments on domestic outputs}

The changes of factor endowments only effect on domestic commodities. This kind of effect just follows the Rybczynski theorem; we will not add it anymore.

\subsection{Comprehensive Tarde effects of factor endowments}

The effect of changes of factor endowments is a very comprehensive effect. We summarize the above analyses as a theorem in following. 
If both commodities continuous to be produced and continues to be traded, a small increase in the supply of a factor will cause:

(a) An increase in the output of the commodity using this factor intensively and a decrease in the output of the other commodity.

(b) A decrease of the relative price of the commodity intensively using this factor and an increase of the relative price of the commodity intensively using another factor.

(c) A decrease of relative price of this factor and an increase of the relative price of another factor.

Statement (a) above actually is the trade effects of the Rybczynski theorem.

Statement (c) actually is the trade effect of the Stolper-Samuelson theorem, which is caused by (a).

Statement (b) engages statement (a) and (b) together. The output changes, sourced from changes of factor endowments, lead to the commodity price change, so the Stolper-Samuelson trade effect happens.

The trade effects here describe the Rybczynski theorem and the Stolper-Samuelson theorem work together jointly. It is a scenario that Rybczynski trade effect triggers the Stolper-Samuelson trade effect. However, a single effect of either the Rybczynski theorem or the Stolper-Samuelson is very different from the joint effect.

Market responses the (small) increase of any factor endowment in a country by identifying and signaling which factor is scarce worldwide to adjust economy to maximize productions and consumptions by prices.

A small increase of any factor endowment in the home country causes the relative more increase of output of commodity intensively used this factor. Its price should fall to increase competition in the world market to help to realize its sales in the market. Another factor in the country then is a relatively scarce domestically and internationally. The higher relative return of that factor causes the future increases of its supply.

Given a set of exogenous factor endowments $L^{F}, L^{H}, K^{H}$, and $L^{H}$, the commodity price under factor price equalization is best prices for the commodity using intensively with its abundant factor for each country. No way to improve its reward domestically (Such as an increase of any factor, except economic decrease). Meanwhile, it reserved domestic pressure to increase reward another factor. This is a new result from trade equilibrium. It is much different from the analysis from autarky to free trade.

A movement to free trade causes the bi-nation economy networked together to share productions and consumptions. The development of a country will cause its counterpart producing more quantities of the commodity using intensively another factor. The relatively scarce factor identified by market worldwide will grow fast due to the rise of its real return.

\subsection{The magnification effect}

Jones (1965) proposed a very useful tool, the magnification effect, which can illustrate trade effects more clearly. We use his method to display the trade effect above by the following:

$$
\begin{aligned}
& \Delta K^{W} \uparrow: \quad \quad \widehat{w}^{*} \uparrow>0>\hat{p}_{1}^{*} \downarrow>\hat{r}^{*} \downarrow \\
& \Delta L^{W} \uparrow: \quad \widehat{w}^{*} \downarrow>0>\hat{p}_{1}^{*} \uparrow>\hat{r}^{*} \uparrow \\
& \Delta K^{H} \uparrow: \quad \hat{x}_{1}^{H} \uparrow>\widehat{K}^{H} \uparrow>0>\hat{x}_{2}^{H} \downarrow \quad \rightarrow \quad \widehat{w}^{*} \uparrow>0>\hat{p}_{1}^{*} \downarrow>\hat{r}^{*} \downarrow \\
& \Delta L^{H} \uparrow: \quad \hat{x}_{1}^{H} \downarrow<0<\hat{L}^{H} \uparrow<\hat{x}_{2}^{H} \uparrow \quad \rightarrow \quad \widehat{w}^{*} \downarrow>0>\hat{p}_{1}^{*} \uparrow>\hat{r}^{*} \uparrow
\end{aligned}
$$

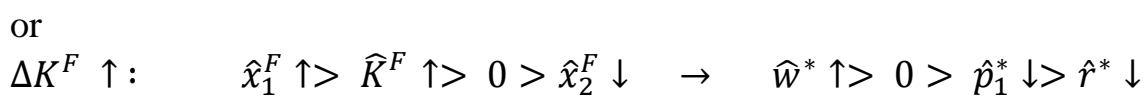

$$
\begin{aligned}
& \Delta L^{F} \uparrow: \quad \hat{x}_{1}^{F} \downarrow<0<\hat{L}^{F} \uparrow<\hat{x}_{2}^{F} \uparrow \quad \rightarrow \quad \widehat{w}^{*} \downarrow>0>\hat{p}_{1}^{*} \uparrow>\hat{r}^{*} \uparrow
\end{aligned}
$$

Beware that we assumed that commodity 1 is capital-intensive (the first commodity intensive in the first factor), i.e. $K^{H} / K^{F}>L^{H} / L^{F}$ and $a_{1 K} / a_{2 K}>a_{1 L} / a_{2 L}$. 
We refer it to comprehensive magnifications of the trade effects

\subsection{A numerical example}

We present a numerical example here to describe the trade equilibrium and trade effects proposed.

Consider two countries, home and foreign, two commodities, 1 and 2, two factors, capital, and labor. The technological matrix is

$\left[\begin{array}{ll}a_{1 K} & a_{2 K} \\ a_{1 L} & a_{2 L}\end{array}\right]=\left[\begin{array}{ll}3 & 1 \\ 1 & 2\end{array}\right]$

The factor endowments in the two countries are

$\left[\begin{array}{c}K^{H} \\ L^{H}\end{array}\right]=\left[\begin{array}{l}2400 \\ 1700\end{array}\right], \quad\left[\begin{array}{c}K^{F} \\ L^{F}\end{array}\right]=\left[\begin{array}{l}1800 \\ 2300\end{array}\right]$

The outputs of two countries by full employment are separate as

$\left[\begin{array}{l}x_{1}^{H} \\ x_{2}^{H}\end{array}\right]=\left[\begin{array}{l}620 \\ 540\end{array}\right], \quad\left[\begin{array}{l}x_{1}^{F} \\ x_{2}^{F}\end{array}\right]=\left[\begin{array}{c}260 \\ 1020\end{array}\right]$

Commodity 1 is K-intensive and commodity 2 is L-intensive. The factor abundant ranking is that the home country is capital abundant and foreign country is labor abundant. The trade direction is that home country exports commodity 1 and foreign country exports commodity 2 .

The share of GNP of the home country is calculated as 0.4982 , based on factor endowments across countries.

The consumption, export, and prices, under free trade, reach the following equilibrium:

$\left[\begin{array}{l}c_{1}^{H} \\ c_{2}^{H}\end{array}\right]=\left[\begin{array}{l}438.42 \\ 777.21\end{array}\right], \quad\left[\begin{array}{l}c_{1}^{F} \\ c_{2}^{F}\end{array}\right]=\left[\begin{array}{l}441.57 \\ 782.78\end{array}\right], \quad\left[\begin{array}{c}T_{1}^{H} \\ T_{2}^{H}\end{array}\right]=\left[\begin{array}{c}181.57 \\ -237.21\end{array}\right]$

$\left[\begin{array}{l}p_{1}^{*} \\ p_{2}^{*}\end{array}\right]=\left[\begin{array}{l}3.8571 \\ 2.9523\end{array}\right],\left[\begin{array}{c}r^{*} \\ w^{*}\end{array}\right]=\left[\begin{array}{l}0.9523 \\ 1.0000\end{array}\right]$

We now analyze trade effects. When the capital endowment in the home country increases 0.5 percent now, the prices and commodity output will be

$\left[\begin{array}{c}K^{H} \\ L^{H}\end{array}\right]=\left[\begin{array}{c}2412 \uparrow \\ 1700\end{array}\right], \quad\left[\begin{array}{c}x_{1}^{H} \\ x_{2}^{H}\end{array}\right]=\left[\begin{array}{c}620.80 \uparrow \\ 539.60 \downarrow\end{array}\right], \quad\left[\begin{array}{c}p_{1}^{*} \\ p_{2}^{*}\end{array}\right]=\left[\begin{array}{c}3.8557 \downarrow \\ 2.9519 \downarrow\end{array}\right],\left[\begin{array}{c}r^{*} \\ w^{*}\end{array}\right]=\left[\begin{array}{c}0.9519 \downarrow \\ 1.0000 \uparrow\end{array}\right]$,

When the labor endowment in the foreign country increases by 0.5 percent, the prices and output will be

$\left[\begin{array}{c}K^{F} \\ L^{F}\end{array}\right]=\left[\begin{array}{c}1800.00 \\ 2302.00 \uparrow\end{array}\right], \quad\left[\begin{array}{l}x_{1}^{F} \\ x_{2}^{H}\end{array}\right]=\left[\begin{array}{c}296.0 \downarrow \\ 1021.90 \uparrow\end{array}\right]$,

$\left[\begin{array}{l}p_{1}^{*} \\ p_{2}^{*}\end{array}\right]=\left[\begin{array}{l}3.8585 \uparrow \\ 2.9528 \uparrow\end{array}\right],\left[\begin{array}{l}r^{*} \\ w^{*}\end{array}\right]=\left[\begin{array}{l}0.9528 \uparrow \\ 1.0000 \downarrow\end{array}\right]$,

\section{Discussion}

The trade effects of this paper can explain some international trade practice. For instance, as China's economic developments, with the interaction with foreign counties, its labor payments increase dramatically those years. The international market incentives its sectors using labor intensively. Those are its sectors with comparative advantages. Its import and exports return new demands on resources and capitals from other countries. That will make incentives to other countries' sectors with comparative advantages. A realistic characteristic of the world is that countries conduct international trade, 
accompanying economic growth. We see the evidence that the development of industries countries and the under-developed countries benefit mutually.

Another expression for Stolper-Samuelson theorem is that free international trade benefits the abundant factor and harms the scarce factor. It is about the process from autarky to free trade. It is not the situation from a free trade equilibrium to another free trade equilibrium. The analysis of this paper says that economic activities after trade, such as the change of factor endowments, benefits another factor, which is then a relatively scarce factor both domestically and internationally by the market. The trade effects from autarky to free trade are much different from the trade effects by trade equilibrium. The trade effects discussed in this paper is for the situations of a continuing trade, under trade equilibrium.

We wish that the studies of this paper could help the Heckscher-Ohlin model stepping in explanations of the dynamics of international trade and economic growth more effectively.

\section{Conclusion}

This paper displays the trade effect based on the price-trade equilibrium. It is a comprehensive trade effect, which engages the Stolper-Samuelson trade effect with the Rybczynski trade effect together. The important conclusion of the trade effects is that any development or changes of a factor endowment of a country, always incentives to another factor both domestically and internationally. In the long-term, another factor will retune back some incentives to that factor. This is a tuneful circle. Trade brings a well-balanced development to the world.

\section{Notes}

(1) We assume that commodity 1 be the relatively capital intensive, and home country is relatively abundant in capital.

(2) This condition will guarantee all possible factor prices are positive. We may refer equation (5) to constraint of the cone of commodity prices, which is a counterpart of the cone of diversification of factor endowments.

\section{References}

Chipman, J.S. (1966), A Survey of the Theory of International Trade: Part 3, The Modern Theory, Econometrica 34, 18-76.

Chipman, J.S. (1969). Factor price equalization and the Stolper-Samuelson theorem. International Economic Review, 10(3), 399-406.

Deardorff, A.V. (1979) Weak Links in the chain of comparative advantage, Journal of International Economics. IX, 197-209.

Deardorff, A.V. (1994) The possibility of factor price equalization revisited, Journal of International Economics, XXXVI, 167-75.

Dixit, A.K. and Norman, V. (1980) Theory of International Trade, James Nisbet, Welwyn, and Cambridge University Press.

Helpman, E. (1984), The Factor Content of Foreign Trade, Economic Journal, XCIV, 84-94.

Helpman, E. and Krugman, P.R. (1985), Market Structure and Foreign Trade, Cambridge, MIT Press.

Baoping, G. (2005), Endogenous Factor-Commodity Price Structure by Factor Endowments International Advances in Economic Research, November, Vol. 11, Issue 4, p. 484.

Guo, B. (2017), World Resources Determine World Price, Munich Personal RePEc Archive, https://mpra.ub.unimuenchen.de/91095/

Guo, B. (2018), Equalized Factor Price and Integrated World Equilibrium, working paper, Available at Munich Personal RePEc Archive, https://mpra.ub.uni-muenchen.de/92051/ 
Jones, R. (1965), The Structure of Simple General Equilibrium Models, Journal of Political Economy 73, 557-572. McKenzie, L.W. (1955), Equality of factor prices in world trade, Econometrica 23, 239-257.

Rassekh, F. and Thompson, H. (1993) Factor Price Equalization: Theory and Evidence, Journal of Economic Integration: Vol 8 No. 1, 1-32.

Samuelson, P.A. (1949), International factor price equalization once again, The Economic Journal 59, $181-197$.

Schott, P. (2003) One Size fits all? Heckscher-Ohlin specification in global production, American Economic Review, XCIII, 686-708.

Vanek, A. (1968), The Factor Proportions Theory: the N-Factor Case, Kyklos, 21(23), 749-756.

Woodland, A. (2013), General Equilibrium Trade Theory, Chapter 3, in Bernhofen, D., Falvey, R., Greenaway, D. and Kreickemeier U. (Eds.), Palgrave Handbook of International Trade, Palgrave Macmillan. 